\title{
Adaptations and modifications to a co- designed intervention and its clinical implementation: a qualitative study in Denmark
}

Jeanette Wassar Kirk ${ }^{1,2^{*}}$, Per Nilsen ${ }^{3}$, Ove Andersen ${ }^{1}$, Nina Thórný Stefánsdóttir ${ }^{1}$, Birk Grønfeldt ${ }^{1}$, Rasmus Brødsgaard ${ }^{1}$, Britt Stævnsbo Pedersen ${ }^{1,4}$, Thomas Bandholm ${ }^{1,5}$, Tine Tjørnhøj-Thomsen ${ }^{6}$ and Mette Merete Pedersen ${ }^{1,7}$

\begin{abstract}
Background: There is a long-standing debate in implementation research on whether adaptations to evidencebased interventions (EBIs) are desirable in health care. If an intervention is adapted and not delivered as conceived and planned, it is said to have low fidelity. The WALK-Cph project was developed based on the assumption that involving stakeholders in co-design processes would facilitate the fidelity of an intervention to increase the mobility of acutely admitted older medical patients and its implementation in two hospitals in Denmark. The purpose of this study is to describe and analyse adaptations and modifications that were made to the co-designed WALK-Cph intervention and its implementation.

Methods: This study used a qualitative design. An ethnographic field study was performed using participant observations, workshops and semi-structured interviews. Data were analysed twice using the Framework Method. The first analysis was based on the frameworks from Stirman, Moore and Proctor. The second analysis, a retrospective modifications analysis, was based on the Adaptation-Impact Framework.

Results: Many different types of adaptations and modifications were made to the WALK-Cph intervention and its implementation plan. Most of the modifications were made on the contents of the intervention. In total, 44 adaptations and modifications were made, of which 21 were planned (adaptations) and 23 were made haphazardly (modifications). Most of the content and context adaptations and modifications made on the intervention had a mixed result regarding enhanced fidelity. The retrospective modifications analysis showed that modifications were ongoing and both situationally and contextually shaped.
\end{abstract}

\footnotetext{
* Correspondence: jeanette.wassar.kirk@regionh.dk

'Present address: Department of Clinical Research, Copenhagen University Hospital, Amager and Hvidovre, Kettegaard alle 30, 2650, Hvidovre, Danmark ${ }^{2}$ Department of Public Health, Nursing, Aarhus University, Nordre Ringgade 1, 8000, Aarhus, Denmark

Full list of author information is available at the end of the article
}

C C The Author(s). 2021 Open Access This article is licensed under a Creative Commons Attribution 4.0 International License, which permits use, sharing, adaptation, distribution and reproduction in any medium or format, as long as you give appropriate credit to the original author(s) and the source, provide a link to the Creative Commons licence, and indicate if changes were made. The images or other third party material in this article are included in the article's Creative Commons licence, unless indicated otherwise in a credit line to the material. If material is not included in the article's Creative Commons licence and your intended use is not permitted by statutory regulation or exceeds the permitted use, you will need to obtain permission directly from the copyright holder. To view a copy of this licence, visit http://creativecommons.org/licenses/by/4.0/. The Creative Commons Public Domain Dedication waiver (http://creativecommons.org/publicdomain/zero/1.0/) applies to the data made available in this article, unless otherwise stated in a credit line to the data. 
Conclusions: Although an extensive co-design process was carried out to facilitate the fidelity of the WALK-Cph intervention, this study showed that many adaptations and modifications were still made to both the intervention and its implementation plan. It could indicate that the co-design process had a small effect or that adaptations and modifications are ongoing and both situationally and contextually shaped, which challenge the assumption and the desire to be able to plan and control changes.

Keywords: Adaptation, Modification, Evidence-based interventions, Qualitative methods, Non-conscious processes

\section{Background}

There is a long-standing debate in implementation research on whether adaptations to evidence-based interventions (EBIs) are desirable in health care [1]. If an intervention is adapted and not delivered as conceived and planned, it is said to have low fidelity [2]. Fidelity refers to the degree to which an intervention or programme is delivered as intended [3]. Such adaptations may influence outcomes [1]. Adaptations of EBIs are difficult or even impossible to avoid when interventions developed in research are implemented in various practice settings [4]. Adaptations are often made to successfully translate new interventions into other settings and ensure their fit with the local context, e.g. the organization and the client population [5]. Identifying processes and types of adaptations of EBIs is important for understanding how to improve the fit between an intervention and the context in which practitioners will use the intervention [6]. Thus, knowledge about adaptation is essential in evaluating the effectiveness of an intervention [7].

Adaptations to EBIs challenge the basic assumption that the core components of an intervention must be implemented with fidelity to achieve its intended effectiveness and expected outcomes [8-10]. Much of the fidelity versus adaptation debate has been theoretical [1], but Durlak [11] has estimated that as much as $80 \%$ of an EBI's prescribed activities may be omitted during implementation. Studies have shown that adaptation to the local context may have both positive and negative impacts on implementation [12-15]. For example, Moore et al. [1] found that adaptations that are made to improve fit do not detract from the core components' positive influence on clinical outcomes. In general, research examining adaptation outcomes show mixed results $[2,4,16]$. Evidence is lacking regarding which outcomes (intervention or implementation outcomes) are influenced by adaptations and whether certain types of adaptations are more likely to influence certain types of outcomes [4].

In the adaptation literature, a distinction is made between adaptations and modifications [1, 2, 17]. Whereas adaptations are planned or proactive [1, 17], modifications are reactive changes made to interventions in response to unanticipated challenges that arise in a given context [17]. Modifications may be implemented somewhat haphazardly for convenience or to save time [4]. In the current study, adaptation refers to planned or purposeful changes to the content and delivery of the new intervention; it does not apply to other original interventions already tested in controlled settings, which adaptation often refers to in literature on adaptation $[1,2,17,18]$.

Adaptations and modifications are often required because EBIs are developed and designed by researchers, programme developers and education organizations separate from clinical practice or other contexts where the intervention will be implemented [2, 4, 7]. In practice, adaptations and modifications are expected when implementing EBIs in routine practice. This recognition has led to the development of a number of frameworks and taxonomies that aim to structure and describe the characteristics of adaptations and modifications $[1,9,17$, 19-22]. Despite these efforts, it remains difficult to fully capture the complexity of adaptation and modification processes, and empirical studies are needed to deepen our understanding of the change processes that interventions undergo when implemented in routine clinical practice $[2,8]$.

When developing EBIs, stakeholder engagement is advocated as a means to reduce research waste, increase value [23] and reduce the need for adaptation during implementation for a better intervention-context fit [24]. The assumption is that when stakeholders, who have a direct interest in the process and outcomes of a project, research or policy endeavour [24], are involved in designing the intervention from the outset, the credibility of the outcomes will improve [25-27]. Engaging stakeholders manifests itself through methods such as codesign [28]. Co-design and co-creation are applied and understood inconsistently in different fields (e.g., community psychology, implementation science, humancentered design) and may look different in different settings, e.g. whether designers are needed to facilitate the process and whether tools and probs are needed [29, 30]. In this study, co-design refers to a methodological approach where stakeholders are involved in designing interventions, and where designers work with people who are not trained in design work together in the development of an intervention. It is usually recommended that stakeholders participate throughout the design process [31]. The assumption is that co-designing an intervention will ensure that the intervention will meet 
stakeholders' present and future needs [31, 32]. In this study, stakeholder engagement is defined as a process with the overall rationale of making use of engagement methods, such as co-design, to increase the quality of a product or an intervention. There are numerous advantages and disadvantages of stakeholder engagement and co-design [33]. For example, stakeholder engagement is considered to improve the quality of the research by enhancing the credibility of the results $[34,35]$. Some practical impacts of co-designing processes are enhanced satisfaction and empowerment for patients and relatives and a greater level of creativity among stakeholders and better relationships between different stakeholders cross sectoral. The broader implications of stakeholder engagement and co-design methods in relation to this study are examined in a different article by Kirk et al. [36]. Therefore, the focus of the present article is adaptations and modifications of a health care intervention.

The co-design literature does not use the concepts of fidelity, adaptation and modifications, but it can be assumed that co-design approaches facilitate a high degree of fidelity and require less adaptations and modifications compared with interventions that are not co-designed with stakeholders. However, there is a knowledge gap on the relationship between co-design and adaptations, if we look at empirical studies in which many focus on codesign [30,37-40] while others focus on adaptations [6, $8,9,14]$. The question is not whether adaptations are made, but whether co-designed interventions prevent modifications, understood as reactive changes implemented somewhat haphazardly for convenience or to save time, and how these modifications influence the clinical and implementation outcomes.

The WALK-Cph project [41] was developed based on the assumption that involving stakeholders in a codesign process would both facilitate the fidelity of the intervention to increase the mobility of acutely admitted older medical patients and facilitate its implementation in two hospitals in Denmark. This patient group has limited mobility during hospitalization [42] and a high prevalence of hospital-associated disability [43]. The purpose of this study is to describe and analyse adaptations and modifications that were made to the codesigned WALK-Cph intervention and its implementation plan. The aim was to investigate why the health professionals and health care managers made adaptations and modifications to the co-designed WALK-Cph intervention and to examine if and how these changes influenced the clinical and implementation outcomes.

\section{Methods}

This study focuses on adaptations and modifications made to the in-hospital components after the development of the intervention and in relation to a subsequent fidelity study. This study is designed as an ethnographic field study, which is well-suited to study experiences of individuals or groups as well as the social interactions and contextual changes [44] in which adaptations occur. Both an ethnographic field study using participant observations [45, 46], workshops and semi-structured interviews were performed [47]. The study is reported using the Standard for Reporting Qualitative research checklist [48] and the Standard for Reporting Implementation Studies [49].

\section{The WALK-Cph intervention}

The intervention outcome of the WALK-Cph project was a $45 \mathrm{~min}$ increase in upright time per day for older medical patients [41]. We have previously shown that older medical patients spend a median of $22 \mathrm{~h}$ per day being inactive during hospitalization in our hospital [50], which is in agreement with a general picture of low inhospital mobility when summarized as level $1 \mathrm{~A}$ evidence across different patient populations, health care settings, and countries [42]. Low mobility increases the risk of functional decline, loss of independence and death [51, 52]. The designed intervention was considered "new" because it was conceptually a new intervention based on a newly designed programme theory (see Additional file 1) [53] and was co-designed [31].

The intervention was co-designed by the research team, health professionals, patients and relatives of the patients [31] in an iterative workshop process of three workshops. Each workshop lasted between 3 and $4 \mathrm{~h}$ and were held in a meeting room in the hospital. The aim of the co-design sessions was to give the stakeholders the possibility to contribute to designing the intervention. The process was facilitated by the research team who coordinated and assisted group discussions and activities during the workshops. The facilitators did not contribute with ideas but encouraged input from participants in their respective groups. Hereafter, the intervention was initiated, and follow-up workshops were held with healthcare professionals and researchers for an overview of adaptations and modification of the intervention. For further details on the co-design process please see Kirk et al., 2021 [36].

The mobility intervention consisted of six in-hospital components (components 1-6) and two post-discharge components (components 7 and 8): (1) welcome folder, (2) WALK-path, (3) posters with physical exercises placed in the wards, (4) physician-prescribed WALKplan, (5) independent collection of clothes, (6) independent collection of beverages, (7) after discharge, patients with a rehabilitation plan were contacted by phone by a municipal therapist or (8) after discharge, patients without a rehabilitation plan were contacted by phone by a municipal health professionals (see Additional file 2). 
The core components of the intervention were considered to be the WALK-path (component 2) and the WALK-plan (component 4) [54]. This study focuses on adaptations and modifications made to the in-hospital components after the initiation of the intervention and during a subsequent fidelity study investigating implementation fidelity.

\section{Study setting}

The study was carried out in Denmark, where the health care system is primarily publicly funded from taxes. The Danish welfare state provides free treatment for primary medical care, hospitals, and home-based care services for all citizens. The WALK-Cph project involved four medical departments at three public hospitals in the Capital Region of Denmark. The four departments encompass six medical specialities: (1) endocrinology; (2) infectious diseases; (3) pulmonary diseases; (4) emergency medicine; (5) gastroenterology; and (6) general medicine. Two of the departments, endocrinology (X) and general medicine $(\mathrm{Y})$, were randomized to the mobility intervention before the co-design process. The two intervention departments are situated in different hospitals and municipalities in Denmark [55].

The two departments are similar in size and staff composition. Department X has 24 beds and 36 staff members consisting of nurses $(n=18)$, certified nursing assistants $(n=6)$ and physicians with responsibility in the department $(n=12)$. Department $Y$ has 25 beds and 37 staff members consisting of nurses $(n=$ $18)$, certified nursing assistants $(n=11)$ and physicians with responsibility in the department $(n=8)$. The therapists are organized differently. In Department X, physiotherapists are called for from a central physio- and occupational therapy department when a patient needs to be attended by a physiotherapist. In Department Y, physiotherapists are part of the multidisciplinary team at the department [55].

\section{Recruitment of participants to the follow-up workshops The participants were recruited from the two intervention departments}

( $\mathrm{X}$ and $\mathrm{Y}$ ) including the department of occupational and physical therapy (Hospital X) and the rehabilitation departments in Municipalities Y. Initially, is was the frontline managers who identified the nurses, nursing assistants, therapists and physicians who had been involved in the design process of the intervention and implementation. These health professionals were selected as they have interest in or experience with designing and implementing an intervention. The follow-up workshops ended up having participation from one physician, three nurses, three nursing assistants, three physiotherapists, three occupational therapists and five frontline managers participated (Table 1).

\section{Data collection}

The data collected for the adaptation and modification analysis in the present study are based on field notes collected during the fidelity study using participant observations and during two follow-up workshops with health professionals and managers, as well as during two subsequent interviews. The fidelity study was conducted over three periods as part of an observational study (4 weeks in each period between September 2018 and March 2019). The first and last authors of this article (JK and MMP) and four research assistants (BG, NS, BSP and $\mathrm{RB})$ were present in both departments during two sessions of $4 \mathrm{~h}$ a day observing the health professionals in their daily practice. Two of the researchers (JK and NS) were trained and had several years of experience using participant observation as a method. The other researchers (MMP, BG, BSP and RB) were trained by initially following JK or NS to observe and learn. Then they performed participant observations where JK or NS participated on the sideline. In addition, the researchers talked together every day, to follow up on situational experiences that the individual researcher needed to discuss e.g. ethical dilemmas. These talks were subsequently written down in the field notes.

The researchers focused on both the fidelity of the intervention and modifications and adaptations to the intervention and the implementation plan. The observation of fidelity was guided by the modified Conceptual Framework for Implementation fidelity developed by Hasson et al. [56], and was described in an observation guide. When fidelity factors from the framework were not met or performed differently than described

Table 1 Health professionals participating in follow-up workshops

\begin{tabular}{llll}
\hline Profession & Number & Years of Experience & Sex \\
\hline Physiotherapists & 3 & $<2,>5,>5$ and $>5$ & 4 females \\
Physician & 1 & $>10$ & 1 female \\
Occupational therapists & 3 & $>5,<2$ and $>2$ & 3 females \\
Nurses & 3 & $<5,>5$ and $>10$ & 3 females \\
Assistant nurses & 3 & $>5,>10$ and $>10$ & 3 females \\
Frontline managers & 4 & $>5,>10,>10$ and $>10$ & 1 man and 3 women \\
\hline
\end{tabular}


(modified) this was written down. If required by the situation, the researcher asked what had been observed. Participant observations were made by following the health professionals in the department or by standing in the hallway by the department's WALK-path. This meant that notes were made both as key words and as full sentences and questions that were raised along the way. After each observation day, the researcher went back to the office and wrote out the field notes, which were placed in a common folder on the research department's drive. Data saturation was achieved when the field observations did not bring new facets to the observations and initial patterns began to emerge in the material. As part of the fidelity study, a common digital diary was used to record reflexive notes concerning thoughts, feelings and observations about adaptations and modifications. These notes were used to discuss pre-understandings and surprises among the researchers and were used as a method to reflect on biases.

The follow-up workshops (September and December 2019) (Table 2) lasted for $3 \mathrm{~h}$ in meeting rooms at the hospitals and were led by JK and MMP; several of the co-authors of this study also participated. At these workshops, initial findings were presented and discussed with the participants. Transcribed material from two audio taped, semi-structured interviews held by JK and MMP with one frontline manager from Department $X$ and one implementation champion from Department $\mathrm{Y}$ was included. The interviews each lasted approximately $1 \mathrm{~h}$ and they were held in meeting rooms at the hospitals. The interview guide was developed with the background of the preliminary results from the fidelity and workshop studies e.g. one finding from the fidelity study, which was put forward in the interviews, was that the welcome folder (an intervention component) was rarely handed out to patients, and the two managers were asked about their considerations on this matter and what they thought could support the use and implementation of the welcome folder. In total, the data material from workshops and interviews consisted of 256 A4 pages (Table 2).

\section{Data analysis}

The data were analysed using the Framework Method [57]. The texts were read twice by JK and an initial qualitative categorization, coding and analysis was performed based on the Adaptation-Impact Framework (AIF) [58]. The AIF [4] includes frameworks from Stirman et al. [2], Moore et al. [1] and Proctor et al. [59] combined in three domains: (1) adaptation or modification descriptions [2]; (2) possible mediating factors [1]; and (3) effect of the adaptation on implementation outcomes [59]. In 2019, Stirman et al. [17] expanded the framework (FRAME) to include components regarding modifications, which are also included in our analysis. In this study, reactive adaptations are referred to as modifications, in line with Stirman et al. [17]. The points of interest in the frameworks are represented in Table 3.

When combining the three frameworks in the AIF, it becomes possible to systematically assess the influence of adaptations on outcomes. In this study, it is only possible to present data on the impact of the adaptations and modifications on implementation outcomes focusing only on the outcomes of acceptability, fidelity and adoption (Additional file 1). Regarding the clinical outcomes, it is only possible to present the expected effect of the adaptations and modifications (unpublished data).

The transcribed data material were first read twice by $\mathrm{JK}$ and then condensed, coded and categorized in a coding scheme constructed with the intervention components and implementation strategies on one axis and adaptation and modifications components from the AIF [58] on the other axis. To secure consistency and rigour in the coding and interpretation of the data material [44], the material was divided into two parts. These two parts were deductively coded by MMP and NS, respectively, based on the AIF. The coded material was compared and discussed by JK, MMP and NS until consensus was reached. Afterwards, discussions were held with the rest of the research team (PN, TTT, TB, OA, RB, BSP, BG) and the results were developed. This iterative process resulted in the findings presented in Table 4 . The results of the analysis are presented in the

Table 2 Data material

\begin{tabular}{llll}
\hline Date and Period & Type of Study & Field Notes & Notes from Semi-structured Interviews \\
\hline September-November 2018 & Fidelity I & 61 pages & \\
January-February 2019 & Fidelity II & 61 pages & \\
February-Mar 2019 & Fidelity III & 65 pages \\
September 2019 & Follow-up workshop I & 33 pages & \\
December 2019 & Follow-up workshop II & 21 pages & \\
January 2019 & Interview with frontline manager X & & 5 pages \\
March 2019 & Interview with implementation champion Y & & 10 pages \\
Total & & 241 pages & 15 pages \\
\hline
\end{tabular}


Table 3 Frameworks included in the analysis

\begin{tabular}{|c|c|c|}
\hline Years & Framework & Points of interest \\
\hline \multirow[t]{4}{*}{2013} & Stirman et al. & Who made the adaptations? \\
\hline & & What was adapted? \\
\hline & & What was the level of the adaptation (e.g. content or context, individual patient or group of patients)? \\
\hline & & What was the nature of the adaptation (e.g. tailoring or adding)? \\
\hline \multirow[t]{3}{*}{2019} & The FRAME framework & Was the adaptation planned? \\
\hline & & What were the goals of the adaptation? \\
\hline & & What were the reasons for the adaptation (e.g. sociopolitical, organizational)? \\
\hline \multirow[t]{3}{*}{2013} & The Framework of Moore & $\begin{array}{l}\text { The fit can be either philosophical (i.e. aligned with the views of the practitioners and the organization) or } \\
\text { logistical (i.e. aligned with the context and understood as, e.g. capacity, skills, and knowledge) }\end{array}$ \\
\hline & & The timing of the adaptation can be either proactive (i.e. planned) or reactive (i.e. haphazardly) \\
\hline & & $\begin{array}{l}\text { The valence considers whether the adaptation aligns with the intervention's goals, i.e. its core components, and } \\
\text { can be either positive (i.e. aligned), neutral (i.e. neither aligned with nor deviated from) or negative (i.e. deviated } \\
\text { from). }\end{array}$ \\
\hline 2011 & Proctor's framework & Acceptability, adoption, appropriateness, feasibility, fidelity, implementation cost and sustainability \\
\hline
\end{tabular}

form of general patterns in relation to adaptations and modifications of the intervention components and of the implementation strategies.

. First, adaptations and modifications were described using the framework from Stirman et al. $[2,17]$ to see how adaptations or modifications influenced outcomes. Then, the framework from Proctor et al. [59] was used to describe which types of adaptations or modifications influenced which outcomes and in which directions. Finally, constructs from the Moore et al. framework [1] were used to explain why and how outcomes were influenced [4] (Tables 5, 6, 7, 8, 9, 10, 11 and 12). A second deductive analysis was done using the AIF framework retrospectively and is presented with three empirical examples at a micro, meso and macro level.

\section{Trustworthiness}

The trustworthiness of the findings is sought to be obtained through credibility by of the use of methods such as participant observations and workshops, which are well established in qualitative research and are wellsuited to study adaptations and modifications in daily practice [60]. Credibility was further obtained by the researchers' engagement in the field with participants both by participant observations over three periods and by several workshops, where the researchers invested time to become familiar with the context, to build trust with the participants and to obtain rich data [60]. In the workshops, initial findings were presented to the participants to continue the analysis and to validate concepts as modifications and adaptations to further strengthen the credibility [61]. The feed back of the initial findings gave the participants the opportunity to comment on the findings and thereby continue the analysis on a more abstract level. Transferability of the finings is difficult to achieve as the modifications and adaptation are tied to the times and the contexts in which they are found. Through the study, thick descriptions of the context has been attempted, e.g. in the retrospective analysis, to provide a possibility to transfer the findings to other contexts [62]. Trustworthiness was also strengthened by using method triangulation in terms of using data both from the field study, the workshops and the interviews [62]. Finally, reflexivity was sought by means of the researchers' use of a common digital diary as a method to reflect on biases and secure confirmability [60].

\section{Results}

\section{Numbers of adaptations and modifications}

Many different types of adaptations and modifications were made throughout the implementation of the WALK-Cph intervention (see Table 4). In total, 21 adaptations (planned) and 23 modifications (haphazard) were made. Of the 44 modifications and adaptations, 33 were made in Department X and 11 in Department Y. Thirtyeight of the modifications and adaptations were made in the implementation phase, five modifications and adaptations were made in the pre-implementation phase and only one adaptation was considered for the scale-up phase. Thirty-seven of the 44 adaptations and modifications were made regarding content and seven were made regarding context.

\section{Content adaptations and modifications}

The adaptations and modifications were mostly initiated and executed by individual practitioners (frontline managers) and teams of practitioners (implementation champions and managers). The adaptations and modifications to the content were predominantly made at a group level (for older medical patients) and at a department level 
Table 4 Overview of all adaptations to intervention components

\begin{tabular}{|c|c|c|c|c|c|}
\hline $\begin{array}{l}\text { Intervention } \\
\text { Component }\end{array}$ & $\begin{array}{l}\text { Department } \\
\mathrm{X} / \mathrm{Y}\end{array}$ & $\begin{array}{l}\text { Number of } \\
\text { Adaptations }\end{array}$ & $\begin{array}{l}\text { Content or } \\
\text { Context } \\
\text { Adaptation }\end{array}$ & Descriptions of the Adaptations & $\begin{array}{l}\text { When Did the } \\
\text { Adaptation } \\
\text { Occur? }\end{array}$ \\
\hline \multirow[t]{17}{*}{ WALK-plans } & $x$ & 1 & Content & $\begin{array}{l}\text { Patients who have not been assigned a WALK-plan are marked } \\
\text { with a minus sign on the board in the staff room. This is to ensure } \\
\text { that all health professionals are made aware that a decision has } \\
\text { been made about WALK-plans for the patient in question }\end{array}$ & Implementation \\
\hline & $x$ & 2 & Content & A rack for WALK-plans is installed & $\begin{array}{l}\text { Pre- } \\
\text { implementation }\end{array}$ \\
\hline & $x$ & 3 & Content & $\begin{array}{l}\text { Changes in time and timing of board meetings, where WALK- } \\
\text { plans are discussed }\end{array}$ & Implementation \\
\hline & $x$ & 4 & Content & $\begin{array}{l}\text { Changes in the interprofessional collaboration in relation to } \\
\text { WALK-plans by which the physicians did not have a part in the } \\
\text { intervention }\end{array}$ & Implementation \\
\hline & $x$ & 5 & Content & $\begin{array}{l}\text { It is discussed whether WALK-plans should be described in the } \\
\text { care plan or in the discharge report/rehabilitation plan, and it is } \\
\text { agreed that the WALK-plans should be described in the discharge } \\
\text { report/rehabilitation plan }\end{array}$ & Implementation \\
\hline & $x$ & 6 & Content & $\begin{array}{l}\text { Changing signature on the WALK-plans, so the nurses and physio- } \\
\text { therapists become responsible for signing the WALK-plans }\end{array}$ & Implementation \\
\hline & $x$ & 7 & Content & $\begin{array}{l}\text { Changes in the responsibility for handing out WALK-plans with } \\
\text { shifts from physicians to nurses and physiotherapists }\end{array}$ & Implementation \\
\hline & $x$ & 8 & Content & WALK-plans (home) are not handed out to patients & Implementation \\
\hline & $x$ & 9 & Content & $\begin{array}{l}\text { In-hospital WALK-plans and WALK-plans (home) are merged into } \\
\text { one WALK-plan }\end{array}$ & Implementation \\
\hline & $x$ & 10 & Content & $\begin{array}{l}\text { Sticker with WALK-Cph logo is attached to envelope with wel- } \\
\text { come folder }\end{array}$ & Implementation \\
\hline & Y & 11 & Content & $\begin{array}{l}\text { Patients who have not been assigned a WALK-plan are marked } \\
\text { with a minus sign on the board in the staff room. This is to ensure } \\
\text { that all health professionals are made aware that a decision has } \\
\text { been made about WALK-plans for the patient in question }\end{array}$ & Implementation \\
\hline & Y & 12 & Content & $\begin{array}{l}\text { The WALK-plans are placed behind the patient's bed, so it be- } \\
\text { comes visible for both patients and health professionals }\end{array}$ & Implementation \\
\hline & Y & 13 & Content & $\begin{array}{l}\text { The establishment of a whiteboard with clips and coloured } \\
\text { magnets for WALK-plans located in the staff's room. This is done } \\
\text { to create greater visibility and systematization of the WALK-plan } \\
\text { practice }\end{array}$ & Implementation \\
\hline & Y & 14 & Content & $\begin{array}{l}\text { Changes in the responsibility for signing and handing out WALK- } \\
\text { plans shifting from physicians to physiotherapists }\end{array}$ & Implementation \\
\hline & $x$ & 1 & Context & $\begin{array}{l}\text { Implementation champions become responsible for board } \\
\text { meetings when frontline managers are unavailable }\end{array}$ & Implementation \\
\hline & $x$ & 2 & Context & $\begin{array}{l}\text { The WALK-plans are placed behind the patient's bed, so it be- } \\
\text { comes visible for both patients and health professionals }\end{array}$ & Implementation \\
\hline & $x$ & 3 & Context & $\begin{array}{l}\text { WALK-plans are expanded in the rehabilitation department so all } \\
\text { patients, and not only patients enrolled in the WALK-trial, receive } \\
\text { a WALK-plan }\end{array}$ & Implementation \\
\hline \multirow[t]{7}{*}{ WALK-path } & $x$ & 1 & Content & $\begin{array}{l}\text { A sign indicating the length of the WALK-path in metres is placed } \\
\text { on the wall in the department }\end{array}$ & Implementation \\
\hline & $x$ & 2 & Content & Posters are placed on the walls in the patient rooms & Implementation \\
\hline & $x$ & 1 & Context & $\begin{array}{l}\text { The WALK-path is moved into the new building when the depart- } \\
\text { ment moves }\end{array}$ & Scale up \\
\hline & $x$ & 2 & Context & Two therapists help mobilize patients at lunch time & Implementation \\
\hline & $x$ & 1 & Content & The green chairs disappear & Implementation \\
\hline & Y & 1 & Content & $\begin{array}{l}\text { The blue chairs disappear. The chairs were similar to the other } \\
\text { chairs in the ward and were not marked as WALK-chairs }\end{array}$ & Implementation \\
\hline & Y & 2 & Content & Marking of blue chairs to ensure that they do not disappear from & Implementation \\
\hline
\end{tabular}


Table 4 Overview of all adaptations to intervention components (Continued)

\begin{tabular}{|c|c|c|c|c|c|}
\hline $\begin{array}{l}\text { Intervention } \\
\text { Component }\end{array}$ & $\begin{array}{l}\text { Department } \\
\mathrm{X} / \mathrm{Y}\end{array}$ & $\begin{array}{l}\text { Number of } \\
\text { Adaptations }\end{array}$ & $\begin{array}{l}\text { Content or } \\
\text { Context } \\
\text { Adaptation }\end{array}$ & Descriptions of the Adaptations & $\begin{array}{l}\text { When Did the } \\
\text { Adaptation } \\
\text { Occur? }\end{array}$ \\
\hline & & & & their location by the posters & \\
\hline & $x$ & 1 & Content & $\begin{array}{l}\text { Small whiteboards are used periodically by health professionals } \\
\text { and patients }\end{array}$ & Implementation \\
\hline & $x$ & 2 & Content & $\begin{array}{l}\text { The small whiteboards are brought back to life; the } \\
\text { physiotherapists start counting the daily number of rounds that } \\
\text { patients have walked }\end{array}$ & Implementation \\
\hline \multirow[t]{2}{*}{$\begin{array}{l}\text { Independent } \\
\text { collection of } \\
\text { clothes }\end{array}$} & $x$ & 1 & Content & $\begin{array}{l}\text { Signs with sizes and descriptions of clothes are placed on the } \\
\text { shelves in the closet. The placement of clothes in the closet is } \\
\text { changed, so smaller garments are placed at the bottom of the } \\
\text { closet so that patients of smaller stature can reach their sizes }\end{array}$ & Implementation \\
\hline & $x$ & 2 & Content & $\begin{array}{l}\text { Stickers are placed on the outside of the closets to indicate } \\
\text { contents }\end{array}$ & Implementation \\
\hline Welcome folder & $x$ & 1 & Content & $\begin{array}{l}\text { Information about the project is not given when handing out } \\
\text { welcome material and therefore a WALK-logo is added as a } \\
\text { reminder }\end{array}$ & Implementation \\
\hline \multirow{2}{*}{$\begin{array}{l}\text { Independent } \\
\text { collection of } \\
\text { beverages }\end{array}$} & $x$ & 1 & Content & $\begin{array}{l}\text { The refrigerator is moved due to fire hazard. Patients can no } \\
\text { longer access the refrigerator and collect beverages }\end{array}$ & Implementation \\
\hline & Y & 1 & Content & $\begin{array}{l}\text { No one is responsible for ensuring that fresh coffee and other } \\
\text { beverages are placed on a table in the ward for self-service }\end{array}$ & $\begin{array}{l}\text { Pre- } \\
\text { implementation }\end{array}$ \\
\hline \multirow[t]{7}{*}{ Others } & $x$ & 1 & Content & $\begin{array}{l}\text { Reward in the form of cake for staff and patients when the } \\
\text { patients in the department had walked } 10 \mathrm{~km} \text { in total }\end{array}$ & Implementation \\
\hline & $x$ & 2 & Content & $\begin{array}{l}\text { The board of directors are informed about the project and how } \\
\text { many kilometres patients have walked in total }\end{array}$ & Implementation \\
\hline & Y & 1 & Content & $\begin{array}{l}\text { Magnets are placed on the overview board to indicate which } \\
\text { patients have a WALK-plan }\end{array}$ & Implementation \\
\hline & Y & 2 & Content & $\begin{array}{l}\text { The whiteboards to mark rounds are abandoned due to formal } \\
\text { rules for this hospital }\end{array}$ & $\begin{array}{l}\text { Pre- } \\
\text { implementation }\end{array}$ \\
\hline & Y & 3 & Content & $\begin{array}{l}\text { Posters with research findings are placed on the wall along the } \\
\text { WALK-path to motivate health professionals }\end{array}$ & $\begin{array}{l}\text { Pre- } \\
\text { implementation }\end{array}$ \\
\hline & Y & 4 & Content & $\begin{array}{l}\text { Posters with research findings are removed, so that they are no } \\
\text { longer visible }\end{array}$ & Implementation \\
\hline & Y & 1 & Context & $\begin{array}{l}\text { Due to an organizational change in the Danish health care } \\
\text { system, where smaller hospitals are merged with larger ones, } \\
\text { Department } Y \text { closes }\end{array}$ & Implementation \\
\hline \multirow[t]{6}{*}{$\begin{array}{l}\text { Implementation } \\
\text { strategies }\end{array}$} & $x$ & 1 & Content & $\begin{array}{l}\text { Written material placed by the computers as reminders are } \\
\text { forgotten }\end{array}$ & $\begin{array}{l}\text { Pre- } \\
\text { implementation }\end{array}$ \\
\hline & $x$ & 2 & Content & $\begin{array}{l}\text { The physicians talk about the project at physicians' conferences } \\
\text { and at board meetings }\end{array}$ & Implementation \\
\hline & $x$ & 3 & Content & $\begin{array}{l}\text { Increased communication efforts (at staff and morning meetings) } \\
\text { about the WALK-intervention to spread the message about WALK }\end{array}$ & Implementation \\
\hline & $x$ & 4 & Content & $\begin{array}{l}\text { The operational target board is not used in relation to Walk-plans; } \\
\text { no operational target has been set for Walk-plans }\end{array}$ & Implementation \\
\hline & $x$ & 5 & Content & $\begin{array}{l}\text { The frontline manager nurse receives coaching in relation to the } \\
\text { management of the project }\end{array}$ & Implementation \\
\hline & Y & 1 & Content & $\begin{array}{l}\text { Increased communication efforts about the WALK-intervention in } \\
\text { the group of nursing staff to spread the message of WALK }\end{array}$ & Implementation \\
\hline
\end{tabular}

(for health professionals). The only adaptation made at the hospital level was that white boards were not put up on the walls due to formal rules in one of the hospitals, which was located in a protected historic building. One modification was made at a hospital level: all refrigerators in the hospital were removed from the department so that they were no longer accessible to patients. This was a result of a fire in a refrigerator in another 


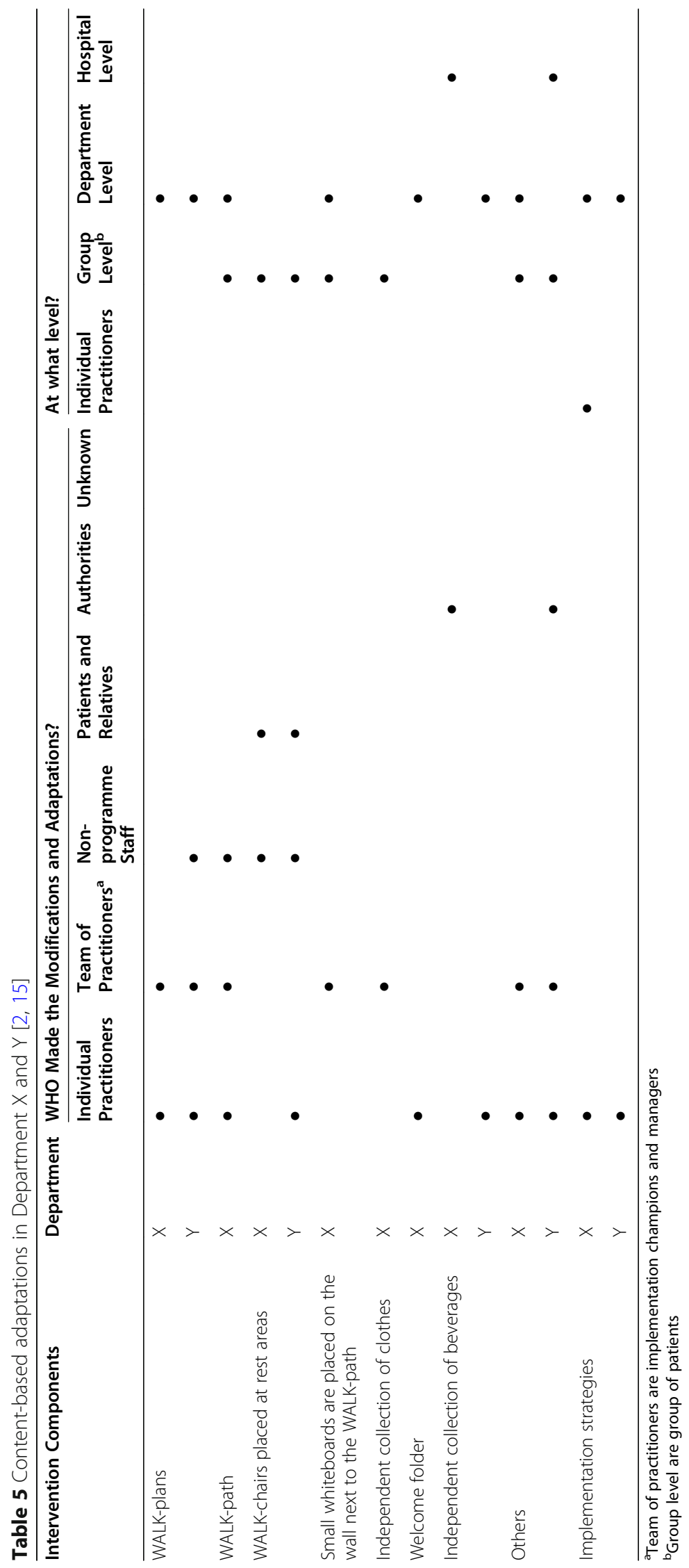




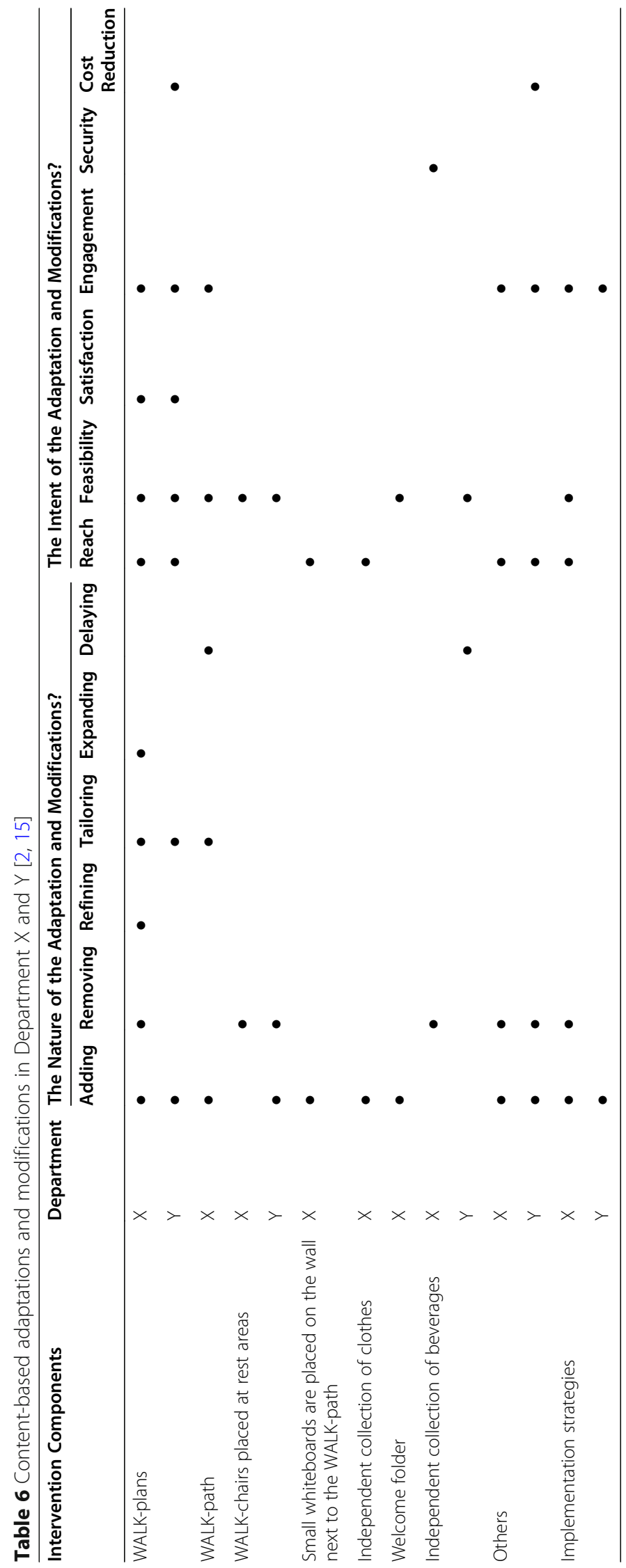




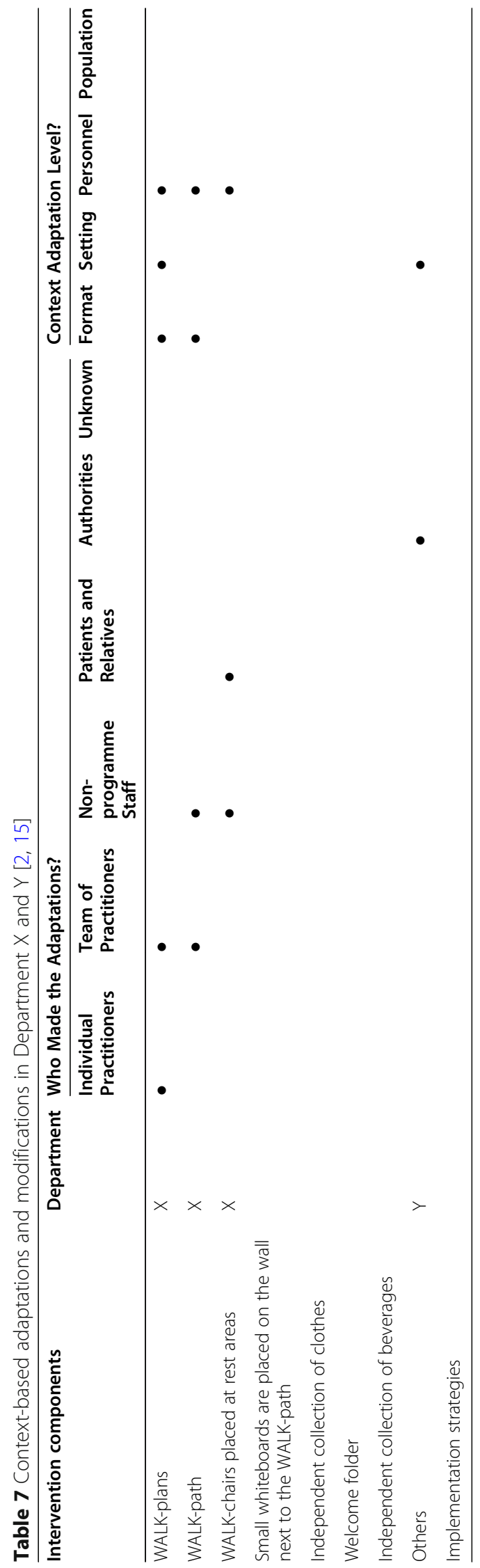




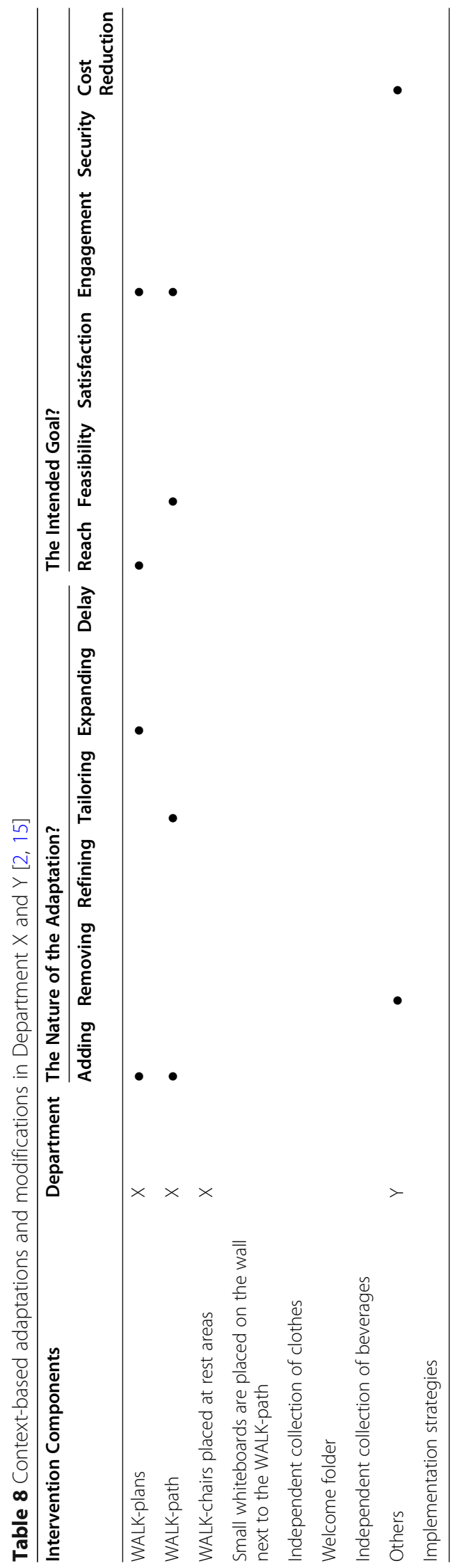


Table 9 Content-based adaptations in Department $X$ and $Y$ [1]

\begin{tabular}{|c|c|c|c|c|c|c|c|}
\hline \multirow[t]{2}{*}{ Intervention Components } & \multirow[t]{2}{*}{ Department } & \multicolumn{2}{|c|}{$\begin{array}{l}\text { Did the } \\
\text { Adaptation } \\
\text { or } \\
\text { Modification } \\
\text { Detract from } \\
\text { Core } \\
\text { Components? }\end{array}$} & \multicolumn{2}{|c|}{$\begin{array}{l}\text { Was It an } \\
\text { Adaptation or a } \\
\text { Modification? }\end{array}$} & \multicolumn{2}{|c|}{$\begin{array}{l}\text { The Rationale for the } \\
\text { Adaptation/Modification? }\end{array}$} \\
\hline & & Yes & No & Planned & Haphazard & $\begin{array}{l}\text { Philosophical } \\
\text { Fit }\end{array}$ & $\begin{array}{l}\text { Logistical } \\
\text { Fit }\end{array}$ \\
\hline \multirow[t]{2}{*}{ WALK-plans } & $x$ & $\bullet$ & $\bullet$ & $\bullet$ & $\bullet$ & $\bullet$ & $\bullet$ \\
\hline & Y & $\bullet$ & $\bullet$ & $\bullet$ & $\bullet$ & $\bullet$ & $\bullet$ \\
\hline WALK-path & $x$ & $\bullet$ & $\bullet$ & & $\bullet$ & & $\bullet$ \\
\hline \multirow[t]{2}{*}{ WALK-chairs placed at rest areas } & $x$ & & $\bullet$ & & $\bullet$ & & $\bullet$ \\
\hline & Y & & $\bullet$ & & $\bullet$ & & $\bullet$ \\
\hline $\begin{array}{l}\text { Small whiteboards are placed on the wall next to the WALK- } \\
\text { path }\end{array}$ & $x$ & $\bullet$ & & $\bullet$ & $\bullet$ & $\bullet$ & \\
\hline Independent collection of clothes & $x$ & & $\bullet$ & $\bullet$ & $\bullet$ & & $\bullet$ \\
\hline Welcome folder & $x$ & & $\bullet$ & $\bullet$ & & & $\bullet$ \\
\hline \multirow[t]{2}{*}{ Independent collection of beverages } & $x$ & $\bullet$ & & & $\bullet$ & & $\bullet$ \\
\hline & Y & $\bullet$ & & & $\bullet$ & & $\bullet$ \\
\hline \multirow[t]{2}{*}{ Others } & $x$ & & $\bullet$ & $\bullet$ & & $\bullet$ & \\
\hline & Y & $\bullet$ & $\bullet$ & $\bullet$ & $\bullet$ & $\bullet$ & $\bullet$ \\
\hline \multirow[t]{2}{*}{ Implementation strategies } & $x$ & & $\bullet$ & $\bullet$ & $\bullet$ & $\bullet$ & $\bullet$ \\
\hline & Y & $\bullet$ & & $\bullet$ & & & $\bullet$ \\
\hline
\end{tabular}

department, which meant that patients could no longer collect beverages themselves, with a negative impact on intervention fidelity.

Most of the content adaptations and modifications related to adding or removing elements, e.g. adding a rack for WALK-plans to make them visible to all health professionals. The intended goals of the content modifications and adaptations were divided between increasing reach, engagement of the intervention and implementation and feasibility. There was no clear pattern on

Table 10 Context-based adaptations and modifications in Department $X$ and $Y$ [1]

\begin{tabular}{|c|c|c|c|c|c|c|c|}
\hline \multirow[t]{2}{*}{ Intervention Components } & \multirow[t]{2}{*}{ Department } & \multicolumn{2}{|c|}{$\begin{array}{l}\text { Did the } \\
\text { Adaptation } \\
\text { or } \\
\text { Modification } \\
\text { Detract from } \\
\text { Core } \\
\text { Components? }\end{array}$} & \multicolumn{2}{|c|}{$\begin{array}{l}\text { Was It an } \\
\text { Adaptation or a } \\
\text { Modification? }\end{array}$} & \multicolumn{2}{|c|}{$\begin{array}{l}\text { The Rationale for the } \\
\text { Adaptation/Modification? }\end{array}$} \\
\hline & & Yes & No & Planned & Haphazard & $\begin{array}{l}\text { Philosophical } \\
\text { Fit }\end{array}$ & $\begin{array}{l}\text { Logistical } \\
\text { Fit }\end{array}$ \\
\hline WALK-plans & $x$ & & $\bullet$ & $\bullet$ & $\bullet$ & $\bullet$ & $\bullet$ \\
\hline WALK-path & $x$ & & $\bullet$ & & $\bullet$ & & $\bullet$ \\
\hline \multicolumn{8}{|c|}{ WALK-chairs placed at rest areas } \\
\hline \multicolumn{8}{|c|}{$\begin{array}{l}\text { Small whiteboards are placed on the wall next to the WALK- } \\
\text { path }\end{array}$} \\
\hline \multicolumn{8}{|c|}{ Independent collection of clothes } \\
\hline \multicolumn{8}{|l|}{ Welcome folder } \\
\hline \multicolumn{8}{|c|}{ Independent collection of beverages } \\
\hline \multicolumn{8}{|l|}{ Others } \\
\hline & Y & $\bullet$ & & $\bullet$ & & $\bullet$ & \\
\hline Implementation strategies & & & & & & & \\
\hline
\end{tabular}




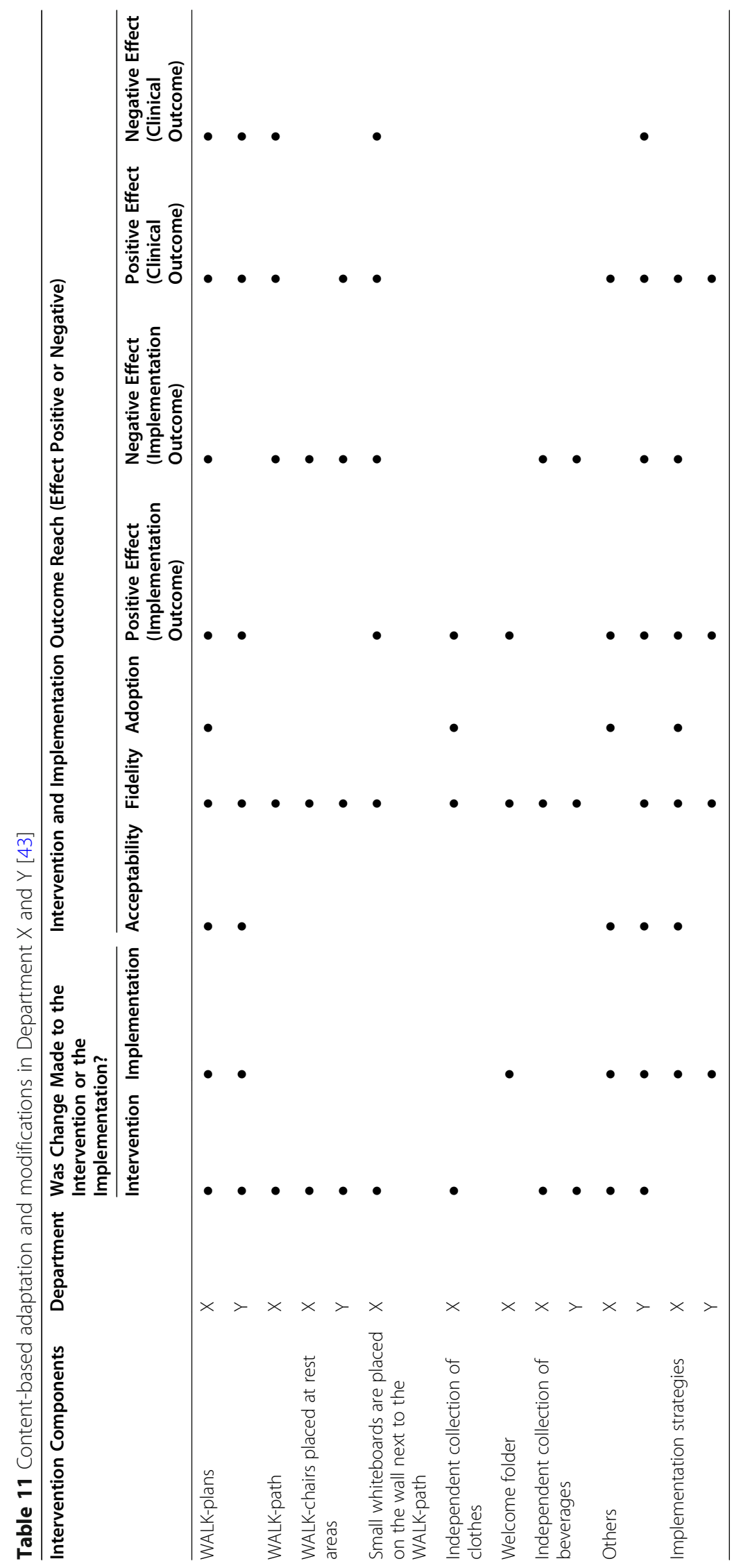




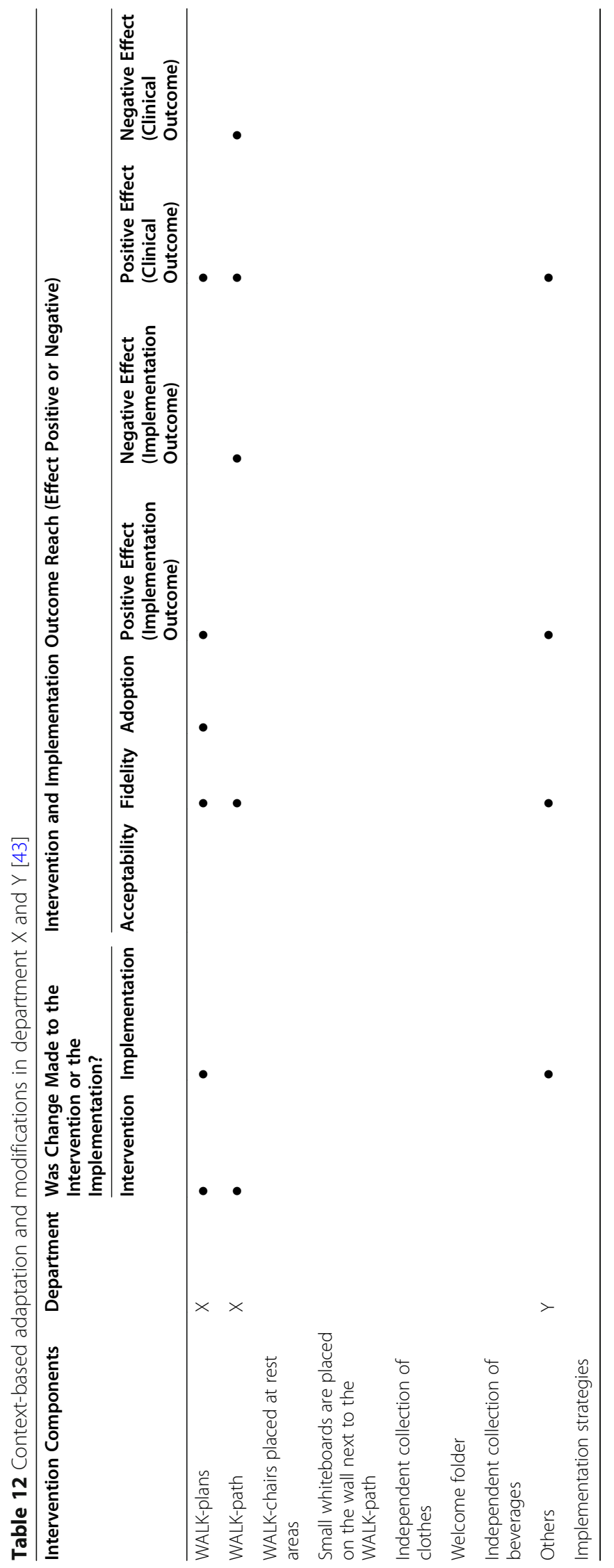


whether content adaptations and modifications detracted from core components. Also, the rationale was mostly for a logistical fit, e.g. stickers were placed on the common-area closets to guide the patients in choosing correct sizes.

\section{Context adaptations and modifications}

Context adaptations and modifications were characterized by being initiated and executed by individual practitioners (frontline managers), teams of practitioners (implementation champions and managers), patients and relatives, non-programme staff and authorities. There was no clear pattern on the levels at which context adaptations and modifications were made. They occurred at levels of format (e.g. the intervention), setting (the intervention was delivered in a different setting) and personnel (the intervention was delivered by changing personnel). Context adaptations and modifications consisted of adding elements with an intended goal of engagement. No context adaptations and modifications detracted from core components and were predominantly made to improve logistical fit.

Most of the content and context adaptations and modifications made on the intervention had a mixed result regarding an intended fidelity effect, e.g. a change in timing of board meetings may have resulted in nonattendance of physiotherapists and thus of discussion of WALK-plans; and a rack for WALK-plans may have facilitated discussion of WALK-plans. However, the expected effect on the clinical outcome of the adaptations and modifications was predominantly positive.

\section{Retrospective modifications analysis}

The results from the retrospective analysis of the complexity of the modifications made haphazardly to the WALK-Cph intervention and implementation are presented through three examples: (1) chairs that went missing (micro level), (2) physicians' lack of commitment to the intervention (meso level) and (3) closure of the intervention in Department Y (macro level).

\section{The missing chairs}

As part of the intervention, two WALK-chairs were placed by the posters showing the exercises in both departments. Throughout the co-design process, these WALK-chairs became a controversial topic. The implementation champions and the managers wanted the chairs to be ergonomically designed with armrests so that older patients could rise correctly from the chairs. The managers explained:" Our current chairs are not usable as they are too heavy, and many do not have armrests" (manager, Department X, interviews). It was also important that they were not too heavy so that the patients could place them correctly when using them for the exercises illustrated on the posters. The WALKchairs in Department X were to be placed in a rest area with other chairs that were too heavy to move. Therefore, the WALK-chairs stood out by having a different colour. The WALK-path was green, and it was requested that the WALK-chairs had a similar green colour to illustrate that they were part of the intervention. In Department $Y$, the WALK-chairs could not differ from the other chairs in colour and shape due to local regulations. All chairs in the department were ergonomically correct (blue chairs with armrests). Thus, the colour of the chairs corresponded to the colour of the WALK-path. The implementation champions put stickers on the two WALK-chairs to make them stand out. In both departments, the hospital architects had to deliver the WALKchairs. This was not a challenge in Department Y, because it was a standard chair. In Department X, however, the colour was a challenge. The architect expressed:" There are rules in the region for which colours may be used in the departments" (architect, Department X, field notes). Green was not in the standard range for furniture at the hospital. Therefore, the architect ended up buying paint and painting the WALKchairs himself before they could be delivered to the department.

The observations showed that in both departments, the WALK-chairs disappeared from their designated areas. Many times, the researchers noted in their observation guide: "Today there is only one green chair placed in the rest area" (researchers, field notes). The WALKchairs were not considered a core component of the intervention, so the lack of WALK-chairs does not impair the core components of the WALK-intervention. The implementation champions and the managers generally did not know where the WALK-chairs had gone. A manager expresses:

"Every day I look for the green chairs and put them back where they belong but the next day they are gone again. That is thought-provoking" (manager, Department $\mathrm{X}$, interviews)

The observations showed that patients and relatives borrowed the WALK-chairs and took them into the patient rooms if a chair was missing or if there were not enough chairs in the room. The green WALK-chairs were easier to move and conspicuous for patients and relatives due to their colour, which may be why they were moved. The same was evident for staff in the neighbouring department (non-programme staff). The modifications were made haphazardly with a logistic fit that had a negative effect on the fidelity of the WALK-intervention because the patients were not able to use the WALKchairs to exercise as illustrated on the posters. 
Physicians' lack of commitment to the implementation of the intervention

The physicians were considered to have a very central role in the intervention to achieve the desired clinical outcome. They had to prescribe WALK-plans for all patients capable of walking and encourage all patients to be physically active during hospitalization. An implementation champion describes: "The physicians are very central to the implementation of the intervention as their words are full of authority for many patients" (implementation champions, Department Y, interviews). They also had to participate in daily board meetings to discuss which patients were eligible for a WALK-plan. In the co-design process, all stakeholders were convinced that the intervention was acknowledged on a philosophical level by physicians, therapists and nursing staff. The physicians' participation was expected to be a core component in relation to the WALK-plans because all stakeholders were confident that the patients would be more compliant and follow physicians' recommendations and would be physically active if a physician told them to be. An implementation champion stated:

"If the physicians, who already prescribe the needed medicine, also - just call it - prescribe uptime. I think that will mean something to most patients. The older generation is still very loyal to authority" (implementation champions, Department Y, workshops).

The observations showed that in practice, the physicians in both departments did not carry out their part of the intervention for many different reasons. When asking one of the implementation champions about this observation, she answered:

We feel that they [the physicians] have not been interested in being involved in any of it, that it is quite clear. They have not really engaged themselves into the project. (Implementation champions, Department Y, workshops)

The only physician who attended the workshops acknowledged this and said:

"You are absolutely right. However, there are many different reasons why my colleagues have not shown so much interest" (physicians, Department $\mathrm{X}$, workshops)

Based on these experiences, the research group decided to systematically examine the physicians' perspective and experiences with the intervention. The results showed multiple reasons for the physicians' lack of commitment. Firstly, the physicians found the interior of the departments unfit for the intervention [63]. Secondly, the physicians did not see mobility as part of their job and responsibility. Finally, the physicians expressed lack of time and resources and therefore unwillingness to accept additional workload [63]. The consequence of the physicians' lack of commitment in the implementation of the intervention was that the implementation champions and managers made multiple modifications to the intervention to enable the physicians' to participate. I.e. on some days, the board meeting was changed to fit the schedule of the physicians and on other days the board meeting was cancelled if the physicians did not have time to participate. The manager commented 1 day on these modifications on a board meeting:" I spend a lot of time finding the physicians and trying to persuade them to attend the board meetings" (manager, Department X, field notes). Also, the nurses and the physiotherapists began to sign the WALK-plans instead of the physicians. Despite all these attempts to accommodate the physicians, the intervention was modified so that only the nurses and physiotherapists were responsible for the intervention. The modifications were made haphazardly with both a philosophical and a logistic fit that had a negative effect on the fidelity and adoption of the implementation of the WALK-intervention and with an excepted negative effect on the clinical outcome.

\section{Closure of intervention department $Y$}

In the implementation phase, Department $\mathrm{Y}$ closed as a result of political decisions. An implementation champion expresses:

"We are very sad that the department has to close. We have adapted the intervention to suit most of the patients in the department" (implementation champion, Department Y, interviews).

Despite the fact that the intervention departments were selected through randomization, and the intervention and the implementation were developed through a long co-design process, it was external factor that became the reason why the intervention and implementation were modified many times in Department Y. Due to the closure of the department, more therapists was relocated to other departments and therefore there were fewer therapists to hand out WALK-plans. When asking an implementation champion about this, she answered:

Department $\mathrm{Y}$ is in bad shape right now; that is, because a lot of health professionals have stopped, and the beds are closed. My colleagues have many other things on their minds than remembering that we 
must hand out WALK-plans. (Implementation champion, Department Y, interviews)

Every day, the few therapists in the department tried to hand out WALK-plans. However, it was done more randomly than described in the intervention, because they also had other tasks to perform. The managers resigned their jobs and therefore there was no managerial support for the project throughout the implementation phase. The consequence was that project was given less attention. The modifications were made haphazardly with a logistic fit that had a negative effect on both the fidelity and adoption of the implementation and a negative effect on the clinical outcome.

\section{Discussion}

The aim of the study was to investigate why health professionals and health care managers made adaptations and modifications to the co-designed WALK-Cph intervention and to examine if and how these changes influenced the clinical and implementation outcomes. The findings showed that 44 modifications and adaptations were made throughout the implementation of the WALK-Cph intervention. Most of the adaptations and modifications were made regarding the contents of the intervention.

The findings from the retrospective modifications' analysis show that modifications were ongoing and both situationally and contextually shaped. The findings illustrate how the implementation of the WALK-Cph intervention occurred on different contextual levels in a social field between people and the daily practice in which they were involved. Despite a large and extensive co-design effort to develop the intervention and an implementation plan that was targeted to the population and the context, there were still many adaptations and haphazard modifications along the way that were not predicted or accommodated before the implementation of the WALK-Cph intervention was initiated.

Our findings showed that implementation champions and managers made both planned adaptations and haphazard modifications to better fit the content and context. This finding is in line with previous studies, which have reported both adaptations and modifications to EBIs $[8,9,64-66]$.

Most of the adaptations and modifications were made on the content in the form of adding or removing elements and tailoring other elements. This predominance of content changes is consistent with previous studies [2, 13, 66]. Contextual adaptations and modifications were less common than content changes in our study. This result is in contrast to Stirman et al. [2] who found context adaptations and modifications to be the next most frequent type of change. Kemp et al. [67] have emphasized context as a potential precondition, moderator or mediator of implementation processes and outcomes. The low number of context adaptations and modifications found in our study may be because the intervention was developed in an extended co-design process with stakeholders, which could have resulted in a better context fit of the intervention from the outset of the implementation [31]. The fit may also have benefitted from the in-depth cultural analysis of the intervention departments involved, which was carried out by the research team. This analysis identified key determinants of mobility of older medical patients during hospitalization [55], knowledge which was also included as part of the co-design process.

Another noteworthy result was the difference in the number of adaptations and modifications made between the two intervention departments. Department X made three times as many adaptations and modifications as Department Y, despite the fact that the departments are similar in many ways, e.g. in size and staff composition. For improved understanding of adaptations and modifications, Escoffery el al [64]. requested descriptions of critical changes and the consequence of these. One example of important adaptations and modifications that emerged was the physicians' lack of commitment to the implementation of the intervention, which resulted in multiple modifications to comply with the physicians' daily practice. This affected the interprofessional collaboration, and in Department Y, the physiotherapists quickly took over the general responsibility for the project and for handing out WALK-plans. This was due to a philosophical fit because mobility is a core competence for therapists, something that was reflected in few context adaptations and modifications as the intervention was adapted to the cultural practice of therapists [55, 68]. These adaptations meant that part of the programme theory (the assumption that the intervention should be interprofessional for most favourable results) was not fulfilled. In contrast, in Department X, the managers and implementation champions struggled to get the physicians involved in the project for a long time. This resulted in Department X making many more adaptations and modifications than Department Y. Despite these attempts, only a few physicians ended up being involved in the project.

Despite the fact that stakeholders were involved in codesigning the intervention and its implementation, as many as 44 adaptations and modifications were made. This was a somewhat surprising finding because the literature suggests that involving stakeholders in co-design processes is an approach to improve the fidelity of interventions. Pérez et al. [69] described how many studies have an implicit assumption: the more an intervention is adapted, the more likely it is that fidelity is threatened 
with the consequence of reduced effectiveness. This perspective suggests that the intervention is an invariant and the users are passive subjects who always implement the intervention with fidelity. In contrast to this view of adaptation/fidelity, our results showed that both adaptations and modifications can be considered cognitive processes involving managers and implementation champions struggling to give meaning to the intervention during its implementation [70] even though they themselves developed the intervention and the implementation plan. An organization such as health care is not a static setting but is constantly evolving and dynamic. Thus, it is inevitable that unforeseen changes will occur that are likely to affect the intervention and its implementation [71] regardless of whether a co-design process was used as recommended [69]. Most frameworks used in implementation science emphasize an active view of organizational context, recognizing that the organization in which implementation occurs is not merely a passive backdrop to implementation [72].

Some adaptations were systematically planned, whereas others occurred more haphazardly. According to descriptions by Moore et al. [1], Stirman et al. [2, 17] and Kirk et al. [73], both adaptations and modifications are always conscious and explicitly recognized changes. However, the question is whether adaptations can also occur more implicitly, without much conscious awareness. The notion of behaviours being guided by nonconscious cognitive processes is not novel. This seems likely in light of research that demonstrates that many behaviours are at least semi-automatic responses to cues triggered by associations outside of our conscious awareness or control [74]. Interest in dual processing approaches has increased significantly, with much attention focused on behaviours resulting from nonconscious processing. Dual process approaches posit that our behaviours are the result of two cognitive processes operating in parallel: an instinctive process and a deliberate, reflective process [75]. Dual process approaches specify a number of boundary conditions that moderate the relationship between conscious and/or nonconscious processes, including cognitive load, stress, and physical or emotional exhaustion [74]. There is strong evidence suggesting that conscious processing decreases steadily over a normal working day as cognitive resources become depleted [76]. We have not found any research on whether or the extent to which adaptations and modifications are the result of non-conscious processes. Such unconscious behaviours challenge existing adaptation frameworks, which have been developed to help control and standardize adaptation processes (e.g. 11 steps in adaptation processes [9]) by potentially functioning completely differently than usually assumed.
The results from this study show that implementing EBIs is a highly dynamic and adaptive process in which the EBIs are adapted to the organization in which the implementation occurs and the organization is adapted to the intervention [77]. The three examples of haphazard modifications in this study show that modifications are ongoing and situationally and contextually shaped. The findings underscore the contextual nature of implementing EBIs as occurs in a social field among people and as part of different contextual levels. Although implementation science originated from the evidence-based medicine movement [78], which views highly controlled interventions as the gold standard, implementation science must be considered a social science where social relations, the context and interdependencies between many factors play a crucial role in influencing the results. The complexities of implementation processes distance implementation science from its medical roots.

The results from this study show that although users are involved in the design of EBIs, it is impossible to predict and account for all eventualities that might occur in the future. In relation to the design of EBIs, it therefore becomes relevant to ask how to best facilitate making EBIs flexible to allow them to be adapted and modified in relation to various contexts and populations and still retain their effectiveness. How can flexibility be built into interventions to optimize their effectiveness in different contexts? This is an area of enquiry that warrants further studies for improved understanding of how EBIs can have the most impact on important outcomes.

\section{Limitations and strengths}

The findings of this study are difficult to generalize to other countries, settings or EBIs. Different adaptations and modifications may be relevant with other EBIs. Although this study makes use of the frameworks of Moore et al. [1], Stirman et al. [2, 17] and Proctor et al. [59] and Kirk [58], the results raise the issue of whether these frameworks can accommodate the social context and the complexity embedded in the context. When interviews are used as the only method to obtain data on adaptations and modifications, it can be especially difficult for health professionals to explicitly recognize and report these. Another limitation is the lack of use of organizational-level profiles of the two departments [65]. However, we have tried to show how adaptation occurs empirically at different levels. Organizational-level profiles early in the co-design phase could perhaps have contributed with additional contextual knowledge about the two departments' approach to adapting initiatives in general.

A further limitation of the study is the lack of involvement of the patients and of knowledge regarding which adaptations and modifications they made while in 
carrying out the intervention. In the field observations, some patient-introduced adaptations and modifications were studied but this was not done systematically. Instead, a systematic interview study was conducted with the patients where their opinions, attitudes, and experience with the intervention was explored [79].

Finally, it may be discussed whether the use of only three outcomes from Proctor's framework had an impact on the results. Acceptability, fidelity and adoption were chosen in this study as these outcomes are highly relevant in the earlier stages of implementation. Proctor et al. [59] also suggest feasibility as a relevant outcome in the early implementation phase. However, using feasibility as an outcome would have required that the study was designed in a more iterative prototyping approach where we develop while testing.

A strength of this study was the use of ethnography with participant observations, where the participants are followed in their daily practice [80]. This method is suitable for revealing the complexity and social reality when interventions are adapted and adopted. Ethnographic research explores what the health professionals say and do, and their relationship with others. Thereby, ethnography is useful for understanding the collective and nonrational dimensions of organizations [68]. By being present in the daily practice of the health professionals, it became clear that parts of the intervention were modified unconsciously e.g., nurses continued to serve patients who had a walking plan, without even noticed it as it was a part of normal practice. Thereby ethnography and participant observations became inherently contextual which shape the interplay between the intervention and the context in which it is implemented.

Finally, there was little researcher involvement in adapting the intervention, allowing us to assess adaptation and modification in naturalistic daily clinical practice and to test the AIF model, which had not been empirically tested previously [58].

\section{Conclusions}

Although an extensive co-design process was carried out to facilitate fidelity of the WALK-Cph intervention, this study showed that many adaptations and modifications were still made to both the intervention and its implementation plan. On the one hand, this could indicate that the co-design process had a small effect. On the other hand, it could indicate that adaptations and modifications are ongoing and both situationally and contextually shaped, which can challenge the assumption and the desire to be able to plan and control changes. The results raise questions of whether all changes are consciously made and point to the need for research to understand how flexibility can be built into EBIs.
This study is an important empirical and analytical contribution to the implementation science field, especially in relation to the fidelity-adaptation debate. It contributes with a perspective on adaptations and modifications as non-conscious processes, which could challenge the established framework developed in the field.

\section{Abbreviations}

EBI: Evidence-based intervention; WALK-Cph: WALK-Copenhagen

\section{Supplementary Information}

The online version contains supplementary material available at https://doi. org/10.1186/s12913-021-07142-4.

\section{Additional file 1.}

Additional file 2.

Acknowledgements

Thank you to all the study participants who let us be a part of their daily practice and gave us the opportunity to interview them.

\section{Authors' contributions}

JK, MMP, TB, OA, PN and TTT designed the study. JK, MMP, BG, NS, RB and BSP collected the data. JK drafted the manuscript. JK, MMP and NN analysed the data. JK interpreted the data and drafted the initial manuscript. PN, Tा, MMP, TB, OA, BG, NN, RB, and BSP critically reviewed the manuscript. All authors read and approved the final manuscript.

\section{Funding}

Funding was granted by The Velux Foundations (grant number F-21835-0104-03); the Association of Danish Physiotherapists (PD-2018-30-10); and the Capital Region of Denmark (P-2018-2-11). The funding bodies had no role in the design of the study and collection, analysis and interpretation of the data and in writing the manuscript.

\section{Availability of data and materials}

The datasets used and analysed during the current study are available from the corresponding author on reasonable request.

\section{Declarations}

\section{Ethics approval and consent to participate}

The study was approved by the Danish Data Protection Agency (AHH-2016080, I-Suite no. 05078). The study is not required to be reported to the ethics committee, cf. section 1, subsection 4 of the Committee Act, and can be carried out without permission from the Research Ethics Committees of the Capital Region. According to Danish law, ethical approval is not mandatory for studies not involving biomedical issues and was, therefore, not obtained [journal nr.: 16035859].

In Denmark, the task of the research ethics committee is to evaluate research projects within health sciences. A health science research project is a project which involves research on live birth human subjects, human sex cells that are intended for fertilization, human fertilized eggs, embryos and fetuses, tissues, cells and hereditary components from humans, fetuses and the like or deceased. This includes clinical trials of pharmaceutical products on humans and clinical trials of medical equipment.

Oral informed consent was obtained from all participants as the project adheres to the directives of the Helsinki Declaration [81]. The head managers acted as gatekeepers and approved our observations in the two

departments. Before undertaking observations, all participants were informed about the aim of the study and were assured that participation was voluntary and that they and the results would be anonymized. Each health professional was given the opportunity to withdraw from being followed in their daily work, but none of the participants did so. Anonymity was ascertained by assigning participants a code instead of using their full names in the field notes. During the field study, we tried to act on situational ethics. 
Thus, we acted with respect to the private space of action of both the older medical patients and the health professionals. If we observed that unplanned changes were made to the components, we asked in an open and reflective way to ensure our understanding of the health professionals' motives for making these changes. We strived to combine our knowledge of the current empirical context with intuition, sense, morality and responsibility [82].

\section{Consent for publication}

Not applicable.

\section{Competing interests}

The authors declare that they have no competing interests.

\section{Author details}

'Present address: Department of Clinical Research, Copenhagen University Hospital, Amager and Hvidovre, Kettegaard alle 30, 2650, Hvidovre, Danmark. ${ }^{2}$ Department of Public Health, Nursing, Aarhus University, Nordre Ringgade 1, 8000, Aarhus, Denmark. ${ }^{3}$ Department of Health, Medical and Caring Sciences, Linköping University, Sandbäcksgatan 7, 58225 Linköping, Sweden ${ }^{4}$ Copenhagen Neuromuscular Center, Rigshospitalet, Inge Lehmanns Vej 8, 2100 Copenhagen $\varnothing$, Denmark. ${ }^{5}$ Department of Orthopedic Surgery, and Department of Physical and Occupational Therapy, Physical Medicine \& Rehabilitation Research-Copenhagen (PMR-C), Copenhagen University Hospital, Amager and Hvidovre, Kettegaards alle 30, 2650 Hvidovre, Denmark. ${ }^{6}$ Department of Health and Social Context, National Institute of Public Health, University of Southern Denmark, Studiestræde 6, 1455 Copenhagen $\mathrm{K}$, Denmark. ${ }^{7}$ Department of Clinical Medicine, University of Copenhagen, Blegdamsvej 3B, 2200 Copenhagen N, Denmark.

\section{Received: 19 January 2021 Accepted: 6 October 2021}

Published online: 16 October 2021

\section{References}

1. Moore JE, Bumbarger BK, Cooper BR. Examining adaptations of evidencebased programs in natural contexts. J Prim Prev. 2013;34(3):147-61. https:// doi.org/10.1007/s10935-013-0303-6.

2. Stirman SW, Miller CJ, Toder K, Calloway A. Development of a framework and coding system for modifications and adaptations of evidence-based interventions. Implement Sci. 2013;8(1). https:/doi.org/10.1186/1748-5908-8-65.

3. Carroll C, Patterson M, Wood S, Booth A, Rick J, Balain S. A conceptual framework for implementation fidelity. Implement Sci. 2007;2(1):40. https:// doi.org/10.1186/1748-5908-2-40.

4. Nilsen P, Birken SA, editors. Handbook on implementation science. Northampton: Edward Elgar Publishing; 2020. https://doi.org/10.4337/9781 788975995.

5. Damschroder LJ, Aron DC, Keith RE, Kirsh SR, Alexander JA, Lowery JC. Fostering implementation of health services research findings into practice: a consolidated framework for advancing. Implement Sci. 2009;4(1):50. https://doi.org/10.1186/1748-5908-4-50.

6. Chambers DA, Norton WE. The Adaptome. Am J Prev Med. 2016;51(4):S12431. https://doi.org/10.1016/j.amepre.2016.05.011.

7. Funnell SC, Rogers PJ. Purposeful program theory: effective use of theories of change and logic models. 1st ed. San Francisco: Jossey-Bass; 2011.

8. Lengnick-Hall R, Fenwick K, Hurlburt MS, Green A, Askew RA, Aarons GA. Let's talk about adaptation! How individuals discuss adaptation during evidence-based practice implementation. J Children's Services. 2019;14(4): 266-77. https://doi.org/10.1108/JCS-05-2018-0010.

9. Escoffery C, Lebow-Skelley E, Udelson H, Böing EA, Wood R, Fernandez ME, et al. A scoping study of frameworks for adapting public health evidencebased interventions. Transl Behav Med. 2019;9(1):1-10. https://doi.org/10.1 093/tbm/ibx067.

10. Hartman MA, Stronks K, Highfield L, Cremer SW, Verhoeff AP, Nierkens V. Disseminating evidence-based interventions to new populations: a systematic approach to consider the need for adaptation. Implement Sci. 2015;10(S1). https://doi.org/10.1186/1748-5908-10-S1-A49.

11. Durlak JA. Why Program Implementation is Important, vol. 15; 1998. https:// doi.org/10.1300/J005v17n02_02.

12. Coronado GD, Schneider JL, Green BB, Coury JK, Schwartz MR, KulkarniSharma $Y$, et al. Health plan adaptations to a mailed outreach program for colorectal cancer screening among Medicaid and Medicare enrollees: the
BeneFIT study. Implementation Sci. 2020;15(1):77. https://doi.org/10.1186/s13 012-020-01037-4.

13. Simione M, Frost HM, Cournoyer R, Mini FN, Cassidy J, Craddock C, et al. Engaging stakeholders in the adaptation of the connect for health pediatric weight management program for national implementation. Implement Sci Commun. 2020;1 (1):55. https://doi.org/10.1186/s43058-020-00047-z.

14. Stanton B, Guo J, Cottrell L, Galbraith J, Li X, Gibson C, et al. The complex business of adapting effective interventions to new populations: an urban to rural transfer. J Adolesc Health. 2005;37(2):163. https://doi.org/10.1016/j.ja dohealth.2004.10.005.

15. Kennedy $\mathrm{M}$, et al. The eccect of tailored a model HIV prevention program for local adolescent target audiences. AIDS Educ Prev. 2000;12(3):225-38.

16. Baker R, Camosso-Stefinovic J, Gillies C, Shaw EJ, Cheater F, Flottorp S, et al. Tailored interventions to overcome identified barriers to change: effects on professional practice and health care outcomes. In: The Cochrane collaboration, editor. Cochrane Database of Systematic Reviews. Chichester: John Wiley \& Sons, Ltd; 2010

17. Wiltsey Stirman S, Baumann AA, Miller CJ. The FRAME: an expanded framework for reporting adaptations and modifications to evidence-based interventions. Implement Sci. 2019;14(1):58. https://doi.org/10.1186/s13012019-0898-y.

18. Hill LG, Maucione K. K. Hood B. a focused approach to assessing program Fidelity. Prev Sci. 2007:8(1):25-34. https://doi.org/10.1007/s11121-006-0051-4.

19. Wiltsey Stirman SA, Gutner C, Crits-Christoph P, Edmunds J, Evans AC, Beidas RS. Relationships between clinician-level attributes and fidelity-consistent and fidelity-inconsistent modifications to an evidence-based psychotherapy. Implement Sci. 2015;10(1):10. https://doi.org/10.1186/s13012-015-0308-z.

20. Aarons GA, Askew RA, Green AE, Yalon AJ, Reeder K, Palinkas LA. Evidencebased practice adaptation during large-scale implementation: a taxonomy of process and content adaptations. J Children's Serv. 2019;14(2):61-77. https://doi.org/10.1108/JCS-02-2018-0003.

21. Bauman LJ, Stein REK, Ireys HT. Reinventing fidelity: the transfer of social technology among settings. Am J Community Psychol. 1991;19(4):619-39. https://doi.org/10.1007/BF00937995.

22. Castro FG, Barrera M Jr, Martinez CR Jr. The cultural adaptation of prevention interventions: resolving tensions between Fidelity and fit. Prev Sci. 2004;5(1):41-5. https://doi.org/10.1023/B:PREV.0000013980.12412.cd.

23. Macleod MR, Michie S, Roberts I, Dirnagl U, Chalmers I, loannidis JPA, et al. Biomedical research: increasing value, reducing waste. Lancet. 2014; 383(9912):101-4. https://doi.org/10.1016/S0140-6736(13)62329-6.

24. Deverka PA, Lavallee DC, Desai PJ, Esmail LC, Ramsey SD, Veenstra DL, et al. Stakeholder participation in comparative effectiveness research: defining a framework for effective engagement. J Comp Effect Res. 2012;1(2):181-94. https://doi.org/10.2217/cer.12.7.

25. Lyon AR, Koerner K. User-centered Design for Psychosocial Intervention Development and Implementation. Clin Psychol Sci Pract. 2016;23(2):180200. https://doi.org/10.1111/cpsp.12154.

26. Domecq JP, Prutsky G, Elraiyah T, Wang Z, Nabhan M, Shippee N, et al. Patient engagement in research: a systematic review. BMC Health Serv Res. 2014;14(1):1. https://doi.org/10.1186/1472-6963-14-89.

27. Trompette J, Kivits J, Minary L, Cambon L, Alla F. Stakeholders' perceptions of transferability criteria for health promotion interventions: a case study. BMC Public Health. 2014;14(1). https://doi.org/10.1186/1471-2458-14-1134.

28. Voorberg WH, Bekkers VJJM, Tummers LG. A systematic review of cocreation and co-production: embarking on the social innovation journey. Public Manag Rev. 2015;17(9):1333-57. https://doi.org/10.1080/14719037.2 014.930505 .

29. Sanders EB-N, Stappers PJ. Probes, toolkits and prototypes: three approaches to making in codesigning. CoDesign. 2014;10(1):5-14. https:// doi.org/10.1080/15710882.2014.888183.

30. Greenhalgh T, Jackson C, Shaw S, Janamian T. Achieving research impact through co-creation in community-based health services: literature review and case study. Milbank Quarterly. 2016;94(2):392-429. https://doi.org/1 0.1111/1468-0009.12197.

31. Sanders EB-N, Stappers PJ. Co-creation and the new landscapes of design. CoDesign. 2008:4(1):5-18. https://doi.org/10.1080/15710880701875068.

32. Simonsen J, Robertson T. Routledge international handbook of participatory design; 2012. https://doi.org/10.4324/9780203108543.

33. Oliver K, Kothari A, Mays N. The dark side of coproduction: do the costs outweigh the benefits for health research? Health Res Policy Systems. 2019; 17(1):33. https://doi.org/10.1186/s12961-019-0432-3. 
34. Barber R, Beresford P, Boote J, Cooper C, Faulkner A. Evaluating the impact of service user involvement on research: a prospective case study: evaluating the impact of service user involvement on research. Int J Consum Stud. 2011;35(6):609-15. https://doi.org/10.1111/j.1470-6431.2011.01 017.x

35. Stewart R, Liabo K. Involvement in research without compromising research quality. J Health Serv Res Policy. 2012;17(4):248-51. https://doi.org/10.1258/ jhsrp.2012.011086

36. Kirk J, Bandholm T, Andersen O, Husted RS, Tjørnhøj-Thomsen T, Nilsen P, et al. Challenges in co-designing an intervention to increase mobility in older patients: a qualitative study. JHOM. 2021; ahead-of-print. https://doi. org/10.1108/JHOM-02-2020-0049.

37. Jessup RL, Osborne RH, Buchbinder R, Beauchamp A. Using co-design to develop interventions to address health literacy needs in a hospitalised population. BMC Health Serv Res. 2018;18(1):989. https://doi.org/10.1186/s12 913-018-3801-7.

38. Norris JM, White DE, Nowell L, Mrklas K, Stelfox HT. How do stakeholders from multiple hierarchical levels of a large provincial health system define engagement? A qualitative study. Implementation Sci. 2017;12(1):98. https:// doi.org/10.1186/s13012-017-0625-5.

39. Castro EM, Malfait S, Van Regenmortel T, Van Hecke A, Sermeus W, Vanhaecht K. Co-design for implementing patient participation in hospital services: a discussion paper. Patient Educ Couns. 2018;101(7):1302-5. https:// doi.org/10.1016/j.pec.2018.03.019.

40. Goodyear-Smith F, Jackson C, Greenhalgh T. Co-design and implementation research: challenges and solutions for ethics committees. BMC Med Ethics. 2015;16(1):78. https://doi.org/10.1186/s12910-015-0072-2.

41. Kirk JW, Bodilsen AC, Tjørnhøj-Thomsen T, Pedersen MM, Bandholm T, Husted RS, et al. A tailored strategy for designing the WalkCopenhagen (WALK-Cph) intervention to increase mobility in hospitalised older medical patients: a protocol for the qualitative part of the WALK-Cph project; 2018. p. 1-8.

42. Fazio S, Stocking J, Kuhn B, Doroy A, Blackmon E, Young HM, et al. How much do hospitalized adults move? A systematic review and meta-analysis. Applied Nursing Research. 2020;51:151189. https://doi.org/10.1016/j.apnr.201 9.151189.

43. Loyd C, Markland AD, Zhang Y, Fowler M, Harper S, Wright NC, et al. Prevalence of Hospital-Associated Disability in Older Adults: A Meta-analysis. J Am Med Directors Assoc. 2020;21:455-461.e5. https://doi.org/10.1016/j.ja mda.2019.09.015

44. Denzin NK, Lincoln YS, editors. The SAGE handbook of qualitative research. 5th ed. Los Angeles London New Delhi Singapore Washington DC Melbourne: SAGE; 2018.

45. Tjørnhøj-Thomsen T, Whyte SR. Fieldwork and participant observation. In: research methods in public health. København: Gyldendal Akademisk; 2008.

46. Hammersley M, Atkinson P. Ethnography: Principles in practice. 2nd ed. London and New York: Routledge; 1995.

47. Kvale S, Brinkmann S. InterView. introduktion til et håndværk. vol. 2. udgave. København: Hans Reitzels Forlag; 2009.

48. O'Brien BC, Harris IB, Beckman TJ, Reed DA, Cook DA. Standards for reporting qualitative research: a synthesis of recommendations. Acad Med. 2014;89(9):1245-51. https://doi.org/10.1097/ACM.0000000000000388.

49. Pinnock H, Barwick M, Carpenter C, Eldrige S, Granders G, Griffiths C, et al. Standards for reporting implementation studies (StaRI) statement. BMJ. 2017;356:i6795. https://doi.org/10.1136/bmj.i6795.

50. Pedersen MM, Bodilsen AC, Petersen J, Beyer N, Andersen O, Smith L, et al. Acute twenty-four-hour mobility during acute hospitalization in older medical patients. J Am Geriatr Soc. 2013;68(3):331-7. https://doi.org/10.1 093/gerona/gls165.

51. Brown CJ, Friedkin RJ, Inouye SK. Prevalence and outcomes of low mobility in hospitalized older patients. J Am Geriatr Soc. 2004;52(8):1263-70. https:// doi.org/10.1111/j.1532-5415.2004.52354.x.

52. Zisberg A, Shadmi E, Sinoff G, Gur-Yaish N, Srulovici E, Admi H. Low mobility during hospitalization and functional decline in older adults: IN-HOSPITAL MOBILITY LEVELS AND FUNCTIONAL DECLINE. J Am Geriatr Soc. 2011;59(2): 266-73. https://doi.org/10.1111/j.1532-5415.2010.03276.x.

53. Curran GM, Bauer M, Mittman B, Pyne JM, Stetler C. Effectivenessimplementation hybrid designs: combining elements of clinical effectiveness and implementation research to enhance public health impact. Med Care. 2012;50(3):217-26. https://doi.org/10.1097/MLR.0b013e31 82408812 .
54. Fixsen DL, Blase KA, Naoom SF, Wallace F. Core Implementation Components. Res Soc Work Pract. 2009;19(5):531-40. https://doi.org/10.11 77/1049731509335549.

55. Kirk JW, Bodilsen AC, Sivertsen DM, Husted RS, Nilsen P, Tjørnhøj-Thomsen T. Disentangling the complexity of mobility of older medical patients in routine practice: an ethnographic study in Denmark. PLoS One. 2019;14(4): e0214271. https://doi.org/10.1371/journal.pone.0214271.

56. Hasson $\mathrm{H}$. Systematic evaluation of implementation fidelity of complex interventions in health and social care. Implement Sci. 2010;5(1). https://doi. org/10.1186/1748-5908-5-67.

57. Gale NK, Heath G, Cameron E, Rashid S, Redwood S. Using the framework method for the analysis of qualitative data in multi-disciplinary health research. BMC Med Res Methodol. 2013;13(1):117. https://doi.org/10.1186/14 71-2288-13-117.

58. Kirk MA. Adaptation. In: Nilsen, P \& Birken, S. Handbook of Implementation Science, Elgar; 2020, p. 317-32.

59. Proctor $E$, Silmere $H$, Raghavan $R$, Hovmand $P$, Aarons $G$, Bunger $A$, et al. Outcomes for implementation research: conceptual distinctions, measurement challenges, and research agenda. Adm Policy Ment Health Ment Health Serv Res. 2011;38(2):65-76. https://doi.org/10.1007/s10488-0100319-7.

60. Shenton AK. Strategies for ensuring trustworthiness in qualitative research projects. EFI. 2004;22(2):63-75. https://doi.org/10.3233/EFI-2004-22201.

61. Morse J. Reframing rigor in qualitative inquiry. In: The SAGE Handbook of Qualitative Research. Den Zin and Lincoln: SAGE Publications, Inc; 2018.

62. Guba EG. ERIC/ECTJ annual review paper: criteria for assessing the trustworthiness of naturalistic inquiries. Educ Commun Technol. 1981;18.

63. Pedersen MM, Brødsgaard R, Nilsen P, Kirk JW. Is promotion of mobility in older patients hospitalized for medical illness a Physician's job? - an interview study with physicians in Denmark. Geriatrics. 2020;5(4):74. https:// doi.org/10.3390/geriatrics5040074.

64. Escoffery C, Lebow-Skelley E, Haardoerfer R, Boing E, Udelson H, Wood R, et al. A systematic review of adaptations of evidence-based public health interventions globally. Implement Sci. 2018;13(1):125. https://doi.org/10.11 86/s13012-018-0815-9.

65. Lengnick-Hall R, Willging CE, Hurlburt MS, Aarons GA. Incorporators, early investors, and learners: a longitudinal study of organizational adaptation during EBP implementation and sustainment. Implementation Sci. 2020; 15(1):74. https://doi.org/10.1186/s13012-020-01031-w.

66. Movsisyan A, Arnold L, Evans R, Hallingberg B, Moore G, O'Cathain A, et al. Adapting evidence-informed complex population health interventions for new contexts: a systematic review of guidance. Implementation Sci. 2019; 14(1):105. https://doi.org/10.1186/s13012-019-0956-5.

67. Kemp CG. Expanding hybrid studies for implementation research: intervention, implementation strategy, and context. Front Public Health. 2019;7:7. https://doi.org/10.3389/fpubh.2019.00325.

68. Hasse C. An anthropology of learning: on nested frictions in cultural ecologies. New York: Springer Berlin Heidelberg; 2014.

69. Pérez D, Van der Stuyft P, del CM Z, Castro M, Lefèvre P. A modified theoretical framework to assess implementation fidelity of adaptive public health interventions. Implement Sci. 2015;11(1):11. https://doi.org/10.1186/ s13012-016-0457-8.

70. Rogers EM. Diffusion of innovations. New York: Free Press; Collier Macmillan; 1983

71. DI F, Sf N, Ka B, Rm F. Implementation research: a synthesis of the literature; 2013.

72. Nilsen $\mathrm{P}$, Bernhardsson S. Context matters in implementation science: a scoping review of determinant frameworks that describe contextual determinants for implementation outcomes. BMC Health Serv Res. 2019; 19(1):189. https://doi.org/10.1186/s12913-019-4015-3.

73. Kirk MA, Moore JE, Wiltsey Stirman S, Birken SA. Towards a comprehensive model for understanding adaptations' impact: the model for adaptation design and impact (MADI). Implementation Sci. 2020;15(1):56. https://doi. org/10.1186/s13012-020-01021-y.

74. Hofmann W, Gschwendner T, Friese M, Wiers RW, Schmitt M. Working memory capacity and self-regulatory behavior: toward an individual differences perspective on behavior determination by automatic versus controlled processes. J Pers Soc Psychol. 2008;95(4):962-77. https://doi.org/1 $0.1037 / a 0012705$.

75. Kahneman D. Thinking, fast and slow. 1st pbk. Ed. New York: Farrar, Straus and Giroux; 2013. 
76. Dai H, Milkman KL, Hofmann DA, Staats BR. The Impact of Time at Work and Time Off From Work on Rule Compliance: The Case of Hand Hygiene in Health Care, vol. 17; n.d.

77. Fonseca J. Conplexity and innovations in organizations. London and New York: Routledge; 2002.

78. Eccles MP, Mittman BS. Welcome to implementation science. Implement Sci. 2006; (1):1-3. https://doi.org/10.1186/1748-5908-1-1.

79. Stefánsdóttir NP, Pedersen MM, Tjørnhøj-Thomsen T, Kirk JW. Older medical patients' experiences with mobility during hospitalization and the WALKCopenhagen (WALK-Cph) intervention: a qualitative study in Denmark. Geriatr Nurs. 2021;42(1):46-56. https:/doi.org/10.1016/j.gerinurse.2020.11.001.

80. Kirk JW, Haines ER. Ethnography. In: Nilsen P, Birken SA, editors. Handbook on implementation science. Northampton: Edward Elgar Publishing; 2020. p. 480-7. https://doi.org/10.4337/9781788975995.00032.

81. Code N. The Nuremberg Code. Trials of War Criminals before the Nuremberg Military Tribunals under Control Council Law; 1949. p. 181-2.

82. Tjørnhøj-Thomsen T. In: Hastrup K, editor. Samværet. Tilblivelse i tid og rum. I: Ind i Verden. En grundbog i antropologisk metode,Kap. 5. pp. 93-116. Hans Reitzels Forlag, 2.udgave, 1.oplag. vol. 2010. Denmark: Hans Reitzels Forlag; 2010. ISBN-13: 978-87-412-2425-1 .

\section{Publisher's Note}

Springer Nature remains neutral with regard to jurisdictional claims in published maps and institutional affiliations.

Ready to submit your research? Choose BMC and benefit from:

- fast, convenient online submission

- thorough peer review by experienced researchers in your field

- rapid publication on acceptance

- support for research data, including large and complex data types

- gold Open Access which fosters wider collaboration and increased citations

- maximum visibility for your research: over $100 \mathrm{M}$ website views per year

At $\mathrm{BMC}$, research is always in progress.

Learn more biomedcentral.com/submissions 